\title{
A mulher negra no capitalismo dependente: aportes sobre cidadania e opressões no Brasil
}

The black woman in dependent capitalism: contributions to citizenship and oppression in Brazil

La mujer negra en el capitalismo dependiente: contribuciones a la ciudadanía y la opresión en Brasil

\author{
Sara Cristina Martins da Silva \\ saracristinamartins96@gmail.com \\ Universidade Federal de Mato Grosso \\ https://orcid.org/0000-0002-5618-5353
}

\begin{abstract}
RESUMO
No presente trabalho, analisamos a situação da mulher negra inserida no sistema capitalista dependente que se desenvolve no Brasil e se apresenta como fonte de opressões e desigualdades. A partir das teorias da dependência e decolonial pretendemos discutir as formas do nó de opressões que afligem a condição de mulher negra, interpelada pelo racismo, pelo machismo e pelo capitalismo. Para tanto, utilizamos a análise bibliográfica de teóricos marxistas, feministas e intelectuais negras que nos situam no debate histórico na busca romper com pensamentos coloniais. Como resultado, percebemos que é imperativo pensar a lógica capitalista, não apenas como um sistema econômico, mas como mantenedor de desigualdades, que impede o exercício de uma cidadania plena e do gozo de direitos por parte das mulheres negras e que as análises sobre esse sistema são incompletas se não incorporados os marcados de raça, gênero e classe social.
\end{abstract}

Palavras-chave: mulheres negras, capitalismo dependente, cidadania, opressões.

\begin{abstract}
In this article, we analyze the situation of black women inserted in the dependent capitalist system that is developing in Brazil and presents itself as a source of oppression and inequalities. Based on dependency and decolonial theories, we intend to discuss the forms of the knot of oppressions that afflict the condition of black women, challenged by racism, machismo and capitalism. For that, we use a bibliographical analysis of Marxist theorists, feminists and black intellectuals who situate us without historical debate in the search to break away from colonial thoughts. As a result, we realize that it is imperative to think of the capitalist logic, not only as an economic system, but as a maintainer of inequalities, which prevents the exercise of full citizenship and the enjoyment of rights by black women and that the analyzes of this system they are incomplete if the marks of race, gender and social class are not incorporated.
\end{abstract}

Keywords: black women, dependent capitalism, citizenship, oppression.

\section{RESUMEN}

En el presente trabajo, analizamos la situación de la mujer negra inserta en el sistema capitalista dependiente que se desarrolla en Brasil y se presenta como fuente de opresión y desigualdades. A partir de las teorías de la dependencia y la descolonización, pretendemos discutir las formas del nudo de la opresión que aquejan la condición de la mujer negra, interpelada por el racismo, el machismo y el capitalismo. Para ello, nos valemos del análisis bibliográfico de intelectuales marxistas, feministas y negros que nos sitúan en el debate histórico en la búsqueda de romper con los pensamientos coloniales. Como resultado, nos percatamos que es imperativo pensar la lógica capitalista, no sólo como un sistema económico, sino como mantenedora de desigualdades, que impide el ejercicio de la ciudadanía plena y el goce de derechos por parte de las mujeres negras y que los análisis de este sistema son incompletos si no se incorporan las marcas de raza, género y clase social.

Palabras clave / Descriptores: Mujeres negras, capitalismo dependiente, ciudadanía, opresiones.

\section{INTRODUÇÃO}

O presente trabalho é resultado do acúmulo adquirido a partir dos debates realizados durante a disciplina denominada “Tópicos Especiais em Serviço Social” do Programa de Pós-Graduação em Política Social da Universidade Federal de Mato Grosso (turma 2020). 
A partir dos debates acerca de temas como Estado, democracia, cidadania, relações de exploração e opressão, travados em sala de aula, é que partimos neste texto, numa análise da influência do capitalismo dependente vivenciado no Brasil, para a constituição de uma cidadania de segunda classe destinada a mulheres negras.

É sabido que as mulheres negras vivem, no Brasil, formas específicas de opressões, cujas raízes estão firmadas no passado colonial e escravocrata, que deu início a uma sociedade de castas, que mais tarde se tornaria uma sociedade de classes extremamente desiguais. Firmados em uma cultura patriarcal que socializa homens e mulheres de formas distintas.

Em que pese, em 1822 ter ocorrido a independência do Brasil em relação à Portugal e em 1888 a abolição da escravidão, esses eventos não significaram mudanças estruturais nas relações raciais e de gênero no país, tendo resultado em um processo de reelaboração das discriminações e execução de um plano de nação que permanecia excluindo pretos, pardos, indígenas e mulheres do exercício da cidadania. O que sustentou o desenvolvimento de uma economia dependente de valores sociais androcentrados.

Este texto parte do questionamento inicial de como o desenvolvimento do capitalismo dependente brasileiro importa na manutenção de desigualdades de gênero e raça que coloca a mulher negra em situação de desvantagem em relação ao exercício pleno da cidadania. Para isso, lançamos mão das teorias da dependência e decolonial, com foco na produção intelectual de mulheres negras.

Enquanto procedimento metodológico, foi adotada a pesquisa por meio da revisão bibliográfica, valendo-se da produção de intelectuais marxistas, como Carlos Nelson Coutinho e Heleieth Saffioti, e feministas negras, como Lélia Gonzalez e Sueli Carneiro.

Num primeiro momento, debateremos a configuração centro/periferia, característica do desenvolvimento capitalista experimentado na América Latina, como produtor da pobreza e sustentáculo das desigualdades de raça, gênero e classe social.

Em seguida, tratamos da constituição do sujeito negro na sociedade capitalista, em especial, da mulher negra, cuja sociabilidade é marcada pela exploração extrema da sua força de trabalho e a marcação de estereótipos que a colocam nas piores posições da sociedade de classes. Por conseguinte, constituindo cidadanias de segundo grau com base nos preconceitos de raças, classe social e gênero.

\section{TEORIA MARXISTA DA DEPENDÊNCIA E DECOLONIALIDADE}

Para uma análise da formação social brasileira, principalmente, uma análise atenta às razões das desigualdades abissais que se verifica quando no debruçamos nas relações estabelecidas entre as 
três raças fundadoras (indígena, negra e branca) são necessários a utilização de métodos e teorias capazes de explicar como a história desses povos foi contado pelo senso comum.

Nesse exercício, constatamos que há uma história oficial pela qual tais desigualdades são, por vezes, naturalizadas como consequência da visão do colonizador sobre esses povos. História essa que justifica a pobreza e a criminalidade como sendo inerentes aos povos vindos de África; a indisposição ao trabalho como inerente aos povos indígenas; e a ciência e o progresso como heranças portuguesas. Tais características se misturam e se reinventam na história nacional, fomentando uma suposta democracia racial.

Para contestar a história oficial, as ciências têm proposto novas teorias e abordagens que dêem conta de desconstruir a pretensão de verdade de uma ciência única e enviesada. Nesse sentido a Teoria Marxista da Dependência se propõe a entender a reprodução do sistema capitalista nos países periféricos, enquanto mecanismo que cria e amplia diferenciações em termos políticos, econômicos e sociais entre países e regiões, de forma que o fracasso econômico de alguns países é condicionado pelo desenvolvimento e expansão de outros (ORTEGAL, 2018).

Em outros termos, é a partir de então que se configura a dependência, entendida como uma relação de subordinação entre nações formalmente independentes, em cujo marco as relações de produção das nações subordinadas são modificadas ou recriadas para assegurar a reprodução ampliada da dependência. (MARINI, 1973, p. 3).

Com especial valor para compreender o desenvolvimento da América Latina, enquanto região periférica que apresenta peculiaridades frente ao modo de produção capitalista estruturado nos países centrais, esta teoria apresenta os instrumentos para compreender as razões para a manutenção da situação de pobreza e profunda desigualdade de grande parte dos países que compõem a região em nome do desenvolvimento econômico e social dos países centrais, em grande parte, do hemisfério norte.

No esteio da tradição marxista, trata-se de uma das mais sólidas contribuições com potencial heurístico para responder às contradições constitutivas do processo capitalista de desenvolvimento na articulação entre sua universalidade e particularidades locais. Isto porque, possibilita-nos i) perceber que é incompreensível o debate do desenvolvimento sem o situarmos historicamente; ii) entender o movimento estrutural e conjuntural do modus operandi do capital como também suas expressões e contradições mais marcantes na permanente dialética entre o atraso e o moderno (MEDEIROS; BEZERRA, 2019, p. 23)

É, portanto, a dicotomia centro x periferia. A existência dessa dicotomia é essencial ao funcionamento do capitalismo, pois a forma como a luta de classes internas se desenvolve no sistema, com a dominação e conformação do ambiente político pela classe dominante, que garante a expansão ou diminuição da dependência da periferia em relação ao centro (MARINI, 1973).

Os Estados-nações periféricos são, nesse contexto, sub soberanos, pois são marcados de relações restritas de soberania frente às formações econômico-sociais de Estados que detêm domínios imperialistas. A sub soberania do Estado no capitalismo dependente implica na 
subordinação/associação do capital e das classes dominantes locais ao capital e às classes soberanas dos países centrais, situação que não representa, em si, um obstáculo ou desvantagem, mas, ao contrário, como uma condição que possibilita a manutenção dos privilégios das classes dominantes locais diante das classes oprimidas. (OSÓRIO, 2014).

Aqui no Brasil, essa teoria é empregada como uma das explicações aos anacronismos típicos do desenvolvimento local. O processo pelo qual a burguesia se consolidou enquanto classe, sem que neste processo houvesse uma ruptura com seu passado colonial, proporcionou um processo de renovação da dependência em relação aos centros hegemônicos do capitalismo de países centrais. A sociedade burguesa brasileira, portanto, movimenta-se no sentido de incorporar características do passado colonial combinadas com a forma moderna de superexploração.

A manutenção da dependência e a articulação entre o atraso e modernização das relações sociais eram, assim, uma exigência da consolidação do poder burguês. A burguesia nascente tinha de "circunscrever a modernização ao âmbito empresarial e as condições imediatas de atividade econômica ou do crescimento econômico" (Fernandes, 2005, p. 242). Corresponder às exigências da industrialização crescentes a partir do século XX exigia conter o crescimento das transformações nos estreitos limites da estrutura concentradora de riqueza e poder herdada do passado [...]. O crescimento econômico sob o capitalismo dependente se converte, assim, no crescimento da própria dependência externa. (MARA; PIRES, 2019, p. 49)

O desenvolvimento de um capitalismo dependente no Brasil é sustentáculo das desigualdades de gênero e raça como condições essenciais ao seu desenvolvimento. Isso porque, a submissão ao mercado internacional, impõe limites internos e externos que acabam por emperrar o crescimento equilibrado das forças produtivas nas regiões subdesenvolvidas.

Ocasionando, a manutenção de uma massa marginal cujas questões relativas ao subemprego e ao desemprego incidem sobre, "no caso brasileiro, os mais baixos níveis de participação na força de trabalho, "coincidentemente", pertencem exatamente às mulheres e a população negra" (GONZALEZ, 2020, p. 27).

A raça, como atributo socialmente elaborado, está relacionada principalmente ao aspecto subordinado da reprodução das classes sociais, isto é, a reprodução (formação-qualificação-submissão) e a distribuição dos agentes. Portanto, as minorias raciais não estão fora da estrutura de classes das sociedades multirraciais em que as relações de produção capitalistas - ou outras relações de produção no caso - são as dominantes. Outrossim, o racismo como articulação ideológica incorporada em e realizada através de uma conjunto de práticas materiais de discriminação, é o determinante primário da oposição dos não brancos (bem como o sexismo) torna-se parte da estrutura objetiva das relações ideológicas e políticas do capitalismo, então a reprodução de uma divisão racial (ou sexual) do trabalho pode ser explicada sem apelar para preconceito e elementos subjetivos. (POULANTZAS, apud: GONZALEZ, 2020, p. 55-56)

Lançando mão de uma outra teoria na busca de compreender a realidade brasileira em suas particularidades, a teoria da decolonialidade é assertiva ao defender as marcas do colonialismo em nossa formação. Segundo essa teoria, as desigualdades do presente, evocam processos estruturados no passado colonial. Mais do que isso, a decolonialidade procura evidenciar o apagamento 
epistêmico que a colonialidade gera sobre os saberes e práticas que há muito tempo denunciam a reprodução do pensamento colonial nas relações da contemporaneidade.

Leonardo Ortegal (2018) afirma que

Nesse processo é possível, então, matizar as realidades nacionais, muitas vezes tratadas de forma homogênea, de modo que os países dominantes se revelam marcados por desigualdades diversas. Isto significa que, além das desigualdades de classe, outros processos são responsáveis por desigualar e assujeitar determinados indivíduos e grupos, por meio da raça, da etnicidade, do gênero e outros. (ORTEGAL, 2018, p. 415)

Nesse contexto, o racismo não é meramente um subproduto ou uma expressão das desigualdades sociais capitalistas. É “insuficiente a tentativa de compreender o racismo no Brasil ignorando a tarefa de situar as relações raciais na estrutura social e econômica em que estão inseridas" (ORTEGAL, 2018, p. 425). Isso porque, enquanto Estado-nação, o Brasil, em grande parte de sua existência, teve como principal força de trabalho pessoas trazidas à força do continente africano e seus descendentes. Estes despojados de seus direitos humanos mais básicos formaram uma massa de desvalidos e desapropriados dos meios de produção capitalista.

A utilização de teorias que desafiam as lógicas coloniais, como as teorias da dependência e decolonial, se apresentam urgentes às ciências, pois rompem com o movimento quase automático de reprodução de desigualdades, em um esforço de crítica às narrativas estabelecidas produzidas pelo colonizador, de reelaboração e "resgate de narrativas e epistemologias que partam de outros lugares, como, por exemplo, do chamado Sul global, por sujeitos que encarnam ou vivenciam essa experiência de subalternização/colonização" (ORTEGAL, 2018, p. 428).

\section{A MULHER NEGRA E A QUESTÃO DA CIDADANIA}

O negro no Brasil, como diz Lélia Gonzalez, está "na lata do lixo da sociedade" (GONZALEZ, 2020), e para justificar tal alegação, podemos observar a problemática dos direitos sociais.

Desde 1948, a ONU reconhece os direitos ao trabalho, ao salário igual por trabalho igual, à previdência social em caso de doença, velhice, morte do arrimo de família e desemprego involuntário, a uma renda condizente com uma vida digna, ao repouso e ao lazer (aí incluindo o direito a férias remuneradas) e o direito à educação, como direitos sociais, que juntamente com os direitos civis e políticos, compõem os direitos humanos. No Brasil, esses direitos foram garantidos em 1988 na Constituição da República.

Todavia, numa análise mesmo que superficial da realidade do país, percebemos um anacronismo entre os princípios igualitários e a realidade de desigualdade e exclusão que se agrava com o avanço do neoconservadorismo e do neoliberalismo, que vem esgotando os já defasados serviços públicos. 
os modelos conhecidos de proteção social vêm sendo postos em xeque pelas atuais mudanças no mundo do trabalho e que conquistas sociais vêm sendo demolidas pela onda neoliberal no mundo inteiro, também é verdade que esse questionamento e essa desmontagem reabrem as tensões, antinomias e contradições que estiveram na origem dessa história. E fazem ver as difíceis (e frágeis) relações entre o mundo social e o universo público da cidadania, na disjunção, sempre reaberta, entre a ordem legal que promete a igualdade e a reposição das desigualdades e exclusões na trama das relações sociais; entre a exigência ética da justiça e os imperativos de eficácia da economia; entre universos culturais e valorativos de coletividades diversas e a lógica devastadora do mercado. (TELLES, 1999, p. 38)

Nas extremidades dos anacronismos há os negros e brancos, ricos e pobres, em tensões raciais que se reinventam a todo tempo. A pesquisa denominada Desenvolvimento humano e desigualdade étnicas no Brasil: um retrato do final do século, elaborada nos anos 2000 pelo economista Marcelo Paixão, nos exemplifica isso. Ela mostra que a desigualdade racial no Brasil é tão intensa que, se o ranking IDH levasse em conta apenas os dados da população branca, o Brasil ocuparia a $48^{\mathrm{a}}$ posição no ranking da ONU. Isso significa que, se brancos e negros tivessem as mesmas condições de vida, o país subiria 26 posições na lista dos 174 países. O contrário, considerando apenas as condições de vida da população negra, o Brasil despencaria para a $108^{\mathrm{a}}$ posição, se igualando a países como a Argélia (PAIXÃO, 2000).

As pesquisas desenvolvidas a respeito das desigualdades sociais no Brasil são essenciais para compreendermos que há uma realidade inegável na qual a população negra brasileira constitui um segmento com características específicas e desvantajosas em termos de interseção social no país (CARNEIRO, 2011).

Ampliando o debate acerca da experiência negra no contexto capitalista, trazemos agora mais um agregador nessa equação, o gênero.

O gênero, nas sociedades capitalistas se apresenta como um marcador da diferença, isso em razão de que o sexo atua como mediador na constituição das trabalhadoras, assim como interfere, de outra parte, na própria diferenciação interna da categoria trabalhadoras. Servindo para regular o grau e a qualidade da absorção da força de trabalho feminina. O fator natural dos sexos sofre variação a depender das necessidades de novos sistemas de bens e serviços. A curto prazo, o emprego da força de trabalho feminina, flutua de acordo com as conjunturas econômicas e a estabilização, a longo prazo, da percentagem que as mulheres representam dos efetivos humanos economicamente ativos, proporção esta, sempre inferior à masculina.

É isso que nos demonstra Saffioti (1976)

a elaboração social do fator sexo não pode ser tomada simplesmente enquanto variável ideológica sem eficácia na produção, mas ao contrário, como fenômeno cujas raízes se incrustam no núcleo econômico do modo de produção capitalista e, neste sentido, como parte construtiva deste, e como contrapartida ideológico da base econômica da sociedade, justificadora das mudanças e diferenciações que permitem a renovação constate das condições de reprodução do modo de produção capitalista" (SAFFIOTI, 1976, p. 9). 
A experiência da mulher negra, nesse contexto, é ainda mais desigual, tendo em vista a interação dos marcadores gênero, raça e classe social. Esses três antagonismos constituem um nó, que potencializam as contradições contidas em cada um desses marcadores, isoladamente (SAFFIOTI, 1987, 1992, 1993).

A mulher negra pós abolição (1888) - período histórico onde no Brasil a ideia de "cidadãos iguais perante a lei” ganha força, mesmo com todas as contradições legais que dessa afirmação se retira - se tornou o sustentáculo moral e econômico de suas famílias e comunidades. Desde esse período, onde feministas liberais brancas lutavam pelo direito ao trabalho e a educação, mulheres negras se dividiam entre o trabalho braçal remunerado e o familiar.

Antes de ir para o trabalho, havia que buscar água na bica comum da favela, preparar o mínimo de alimento para os familiares, lavar, passar e distribuir as tarefas das filhas mais velhas no cuidado dos mais novos. Acordar às três ou quatro horas da madrugada para "adiantar os serviços caseiros" e estar às sete ou oito horas na casa da patroa até a noite, após ter servido o jantar e deixado tudo limpo. Nos dias atuais, a situação não é muito diferente. (GONZALEZ, 2020, p.40)

A inserção prematura e exploratória da mulher negra no mercado capitalista, combinado com a ausência de políticas públicas reparatórias pós abolição voltadas à população negra, obrigaram a mulher negra a ocupar os piores indicadores sociais no que se refere a trabalho, escolarização, moradia e segurança.

Para Heleieth Saffioti (1976),

certos preconceitos de raça e sexo não representam simplesmente uma incapacidade da supra-estrutura ideológica de acompanhar pari passu as mudanças sofridas pela infra-estrutura econômica, mas nutrem da seiva que lhe oferece esta última e proliferam, contraem-se e diferenciam-se segundo as conveniências da base econômica da sociedade." (SAFIOTTI, 1976, p. 8)

A exploração capitalista relegou às mulheres negras os piores cargos, geralmente em serviços braçais como empregada doméstica, babás, serviços gerais, com baixos salários e exaustivas jornadas. O que, por consequência, fez com que a taxa de analfabetismo entre este grupo permanecesse alta.

Excluída da participação no processo de desenvolvimento (desigual e combinado, não esqueçamos), ficou relegada à condição de massa marginal crescente: desemprego aberto ou não, ocupação "refúgio" em serviços puros, trabalho ocasional, ocupação intermitente, trabalho por temporada etc.

[...]

[a mulher negra] se volta para a prestação de serviços domésticos junto às famílias das classes média e alta da formação social brasileira. Enquanto empregada doméstica, ela sofre um processo de reforço quanto à internalização da diferença, da subordinação e da "inferioridade" que lhe seriam peculiares. Tudo isso acrescido pelo problema da dupla jornada que ela, mais do que ninguém, tem de enfrentar. (GONZALEZ, 2020, p. 58)

Isso em razão de que o trabalho, enquanto categoria central de análise da sociedade capitalista, se constitui à mulher negra enquanto elemento da mais profunda alienação. As crises 
típicas do capitalismo servem para acirrar e corroer as condições de trabalho, no mesmo movimento, agudizam as desigualdades raciais e deterioram as condições materiais de vida das mulheres negras, enquanto grupo social mais exposto e elo mais fraco das relações de trabalho.

$\mathrm{Na}$ crise iminente do capital, o exercício da cidadania da mulher negra é, historicamente, sacrificado em prol do desenvolvimento das forças econômicas. De modo que, a cidadania nas sociedades capitalistas, se reveste de uma forma jurídica subordinada ao movimento geral do desenvolvimento do capitalismo. Ou seja, a cidadania apresenta limites, uma vez que a igualdade é incompatível com a sociedade de classes.

Não é ocasional que a forma jurídica encontre a sua maturidade numa sociabilidade em que a forma mercantil adquire a sua plenitude. Desse modo, a forma jurídica vincula-se à existência de uma sociedade que exige a mediação de um equivalente geral para que os diversos trabalhos privados independentes se tornem trabalho social. (FELIX, 2019, p. 20)

Através das desigualdades de raça, gênero e classe social, verificamos no Brasil a existência de subclasses de cidadãos. E diante desse cenário, na condição de mulher negra no Brasil é imperativo a esse grupo pensar alternativas ao mais alto nível de opressão a que estão colocadas. Enquanto habitante da periferia mundial, bem como, da periferia nacional, as mulheres negras têm usado dos instrumentos decoloniais como saída epistemológica para pensar o poder e as narrativas, denunciando o racismo e o sexismo que as interpela.

A classe social, nessa equação, e enquanto expressão típica da sociedade capitalista, é a categoria que dá a sustentação ao nó, de forma que, a cidadania moderna é uma expressão própria da formação social regida pela ordem capitalista, portanto, subordinada a seu movimento, lutar pela sua plena realização, sem que disso derive uma ruptura radical com seus fundamentos, é lutar pelo pleno desenvolvimento capitalista e de todas as consequências que dele decorrem (FELIX, 2019).

Se é na perspectiva da emancipação humana (MARX, 2010) que buscamos encaminhar nossos esforços, a disputa em torno dos espaços do Estado só pode ter como finalidade a preparação para a sua superação. Ora, se não há forma Estado que não expresse interesse de classes, e se uma sociedade emancipada implica na abolição do conjunto das classes sociais, torna-se inviável a permanência desse poder político que, sendo produto das relações sociais estranhadas, só pode expressar poder de classe, radicado no próprio processo de desenvolvimento do capital. (FELIX, 2019, p. 35)

Jurema Werneck (2010), afirma que o imperativo da sobrevivência dá o tom ao desenvolvimento da identidade da mulher negra, o desafio para o futuro nos parece ser a consolidação de uma política de apropriação de espaços de poder, visando a incorporação de uma cidadania plena.

Empenhadas em afirmar suas identidades e exigir o reconhecimento social, a mobilização social de mulheres negras, destituídas de capital social, tanto no passado como no presente é 
baseada na ação coletiva (CARNEIRO, 2003, p. 129), no interior de suas comunidades, nas periferias que habitam, dão o tom da luta social em torno dos direitos sociais.

Carlos Nelson Coutinho, em seu livro "A democracia como valor universal", assinala no sentido de que

As transformações políticas e a modernização econômico-social no Brasil foram sempre efetuadas no quadro de uma "via prussiana", ou seja, através da conciliação entre frações das classes dominantes, de medidas aplicadas de cima para baixo, com a conservação essencial das relações de produção atrasadas (o latifúndio) e com a reprodução (ampliada) da dependência do capitalismo internacional; essas transformações "pelo alto" tiveram como causa e efeito principais, a permanente tentativa de marginalizar as massas populares não só da vida social em geral, mas sobretudo, do processo de formação das grandes decisões políticas nacionais. (COUTINHO, 2018, p. 41)

Ao entender que categorias como raça ou gênero são construídas socialmente e que se trata de um grande e contínuo projeto que subordina pessoas, através de práticas sociais e políticas institucionais. Pensar sobre o modo como o poder e o direito se agrupou em torno de certas categorias é o desafio de teóricos feministas e antirracistas.

\section{CONCLUSÃO}

Como pudemos ver, o debate acerca da questão racial no Brasil é indissociável ao debate acerca do modo de produção capitalista. Tanto por ser um modo de produção que deriva da escravidão e dela até os dias atuais se sustenta, como por ter caráter dependente da ordem mundial que aprisiona e reforça as desigualdades.

Do mesmo modo, neste espaço demonstramos a situação da mulher negra, interpelada pelo machismo, pelo racismo e pela classe social dentro do sistema capitalista, marcadores que acabam por atualizar a dinâmica colonial de opressão e exploração. A realidade exposta exige a reelaboração do pensamento sobre direitos, cidadania e da ordem capitalista sob o viés desse grupo marginalizado.

Como salienta Patrícia Hill Collins (2016), os marcadores sociais de gênero, raça e classe social colocam as mulheres negras em lugares específicos que as permitem ter um olhar tanto da margem onde se encontram quanto do centro onde não podem estar posicionadas. Esse olhar contesta a ideia de pensar os marcadores sociais somente a partir das desvantagens sociais e nos leva a construção de uma ferramenta de empoderamento para as mulheres negras e para além, se mostra como um horizonte teórico e empírico da produção científica acerca da sociedade brasileira.

E é desse lugar específico, ocupado pela mulher negra brasileira, que se concretiza o processo de renovação democrática, enquanto novos sujeitos políticos que flexionam o jogo político para o reconhecimento da força popular, ao que Gramsci chamou de "Guerra de posições" como método para se chegar a uma democracia real, com participação popular e consenso necessário para empreender ações contra o colonialismo e o capitalismo (COUTINHO, 2018). 


\section{BIBLIOGRAFIA}

CARNEIRO, S. Realidade Estatística. In: Racismo, Sexismo e Desigualdade no Brasil. São Paulo: Selo Negro, 2011.

CARNEIRO, S. Mulheres em movimento. São Paulo: Estudos Avançados, v. 17, n. 49, 2003.

COLLINS, P. H. Aprendendo com a outsider within: a significação sociológica do pensamento feminista negro. Brasília: Revista Sociedade e Estado, n. 1, v. 31, p. 99-127, 2016.

COUTINHO, C. N. A democracia como valor universal. Em: TEIXEIRA, A. M. de P.; ALVES, G. L. Carlos Nelson Coutinho: Ensaios de crítica literária, Filosofia e Política. Coleção Carlos Nelson Coutinho. Volume I. Rio de Janeiro: PPGSS/UFRJ, 2018.

ELIAS, M. Lutas sociais, revolução brasileira e projeto popular. Em: MEDEIROS, E.; NOGUEIRA, L.; BEZERRA, L. (Orgs.). Formação Social e Serviço Social: a realidade brasileira em debate. São Paulo: Outras Expressões, 2019.

FELIX, P. R. Cidadania e capitalismo: uma análise a partir da crítica marxista do direito. Rio de Janeiro: Revista Praia Vermelha, v. 29, 2019.

GONZALEZ, L. Cultura, etnicidade e trabalho: efeitos linguísticos e políticos da exploração da mulher. Em: Por um feminismo afro-latino-americano: ensaios, intervenções e diálogos. Org. RIOS, F.; LIMA, M. Rio de Janeiro: Zahar, 2020.

GONZALEZ, L. A mulher negra na sociedade brasileira: uma abordagem político-econômica. Em: Por um feminismo afro-latino-americano: ensaios intervenções e diálogos. Org. RIOS, F.; LIMA, M. Rio de Janeiro: Zahar, 2020.

MARA, E.; PIRES, O. C. Capitalismo dependente, autocracia burguesa e contradições de classe no Brasil. Em: MEDEIROS, E.; NOGUEIRA, L.; BEZERRA, L. (Orgs.). Formação Social e Serviço Social: a realidade brasileira em debate. São Paulo: Outras Expressões, 2019.

MARINI, R. M. A dialética da dependência. Tradução CARCANHOLO, M. México: Editora Era, 10 ed., 1990.

MEDEIROS, E.; BEZERRA, L. Considerações sobre o desenvolvimento desigual e combinado no capitalismo brasileiro. Em: MEDEIROS, E.; NOGUEIRA, L.; BEZERRA, L. (Orgs.). Formação Social e Serviço Social: a realidade brasileira em debate. São Paulo: Outras Expressões, 2019.

MENEGUELLO, R.; MANO M. K.; GORSKIC. Alguns condicionantes do déficit representativo de mulheres e negros na política. Em: MENEGUELLO, R. Et al. Mulheres e negros na política: estudo exploratório sobre o desempenho eleitoral em quatro estados brasileiros. Campinas: UNICAMP/CESOP, 2012.

ORTEGAL, L. Relações raciais no Brasil: colonialidade, dependência e diáspora. São Paulo: Serviço Social \& Sociedade. n. 133, p. 413-431, 2018. https://doi.org/10.1590/0101-6628.151. Acesso em 10 julho de 2021.

OSÓRIO, J. O Estado no centro da mundialização. São Paulo: Outras Expressões, 2014.

PAIXÃO, M. Desenvolvimento humano e as desigualdades étnicas no Brasil: um retrato do final do século XX. Rio de Janeiro: Proposta, ano 29, nº 86, p. 30-51, 2000.

SAFFIOTI, H. I. B. A mulher sob o modo de produção capitalista. São Paulo: Revista Contexto, n. 01, 1976.

SAFFIOTI, H. I. B. Diferença ou indiferença: gênero, raça/etnia, classe social. Em: ADORNO, S. (Org.). A sociologia entre a modernidade e a contemporaneidade. Cadernos de Sociologia. Porto Alegre: Editora da UFRGS, 1993.

SAFFIOTI, H. I. B. Rearticulando gênero e classe social. Em: COSTA, A. O.; BRUSCHINNI, C. (Orgs). Uma questão de gênero. São Paulo: Rosa dos Tentos Editora e Fundação Carlos Chagas, 1992.

SAFFIOTI, H. I. B. O poder do macho. São Paulo: Moderna, 1987.

TELLES, V. S. Direitos Social: afinal do que se trata? Em: Direitos Sociais: afinal do que se trata? Belo Horizonte: UFMG, 1999.

WERNECK, J. Nossos passos vêm de longe! Movimento de Mulheres Negras e Estratégias Políticas contra o Sexismo e o Racismo. Revista da Associação Brasileira de Pesquisadores/as Negros/as (ABPN), v. 01, n. 01, 2010. 